\title{
IN VIVO LOCAL CO-DELIVERY OF RECOMBINANT HUMAN BONE MORPHOGENETIC PROTEIN-7 AND PAMIDRONATE VIA POLY-D, L-LACTIC ACID
}

\author{
Nicole Y.C Yu ${ }^{1,2}$, Aaron Schindeler ${ }^{1,3}$, Lauren Peacock ${ }^{1}$, Kathy Mikulec ${ }^{1}$, Paul A. Baldock ${ }^{4}$, Andrew J. Ruys ${ }^{2}$ and \\ David G. Little ${ }^{1,3}$
}

\begin{abstract}
${ }^{1}$ Department of Orthopaedic Research \& Biotechnology, The Children's Hospital at Westmead, Locked Bag 4001, Westmead, NSW 2145, Australia

${ }^{2}$ School of Aerospace, Mechanical and Mechatronic Engineering, J07 University of Sydney, NSW 2006, Australia ${ }^{3}$ Discipline of Paediatrics and Child Health, Faculty of Medicine, A27 University of Sydney, NSW 2006, Australia

${ }^{4}$ Osteoporosis and Bone Biology Research Program, Garvan Institute of Medical Research, 384 Victoria St, Darlinghurst, NSW 2010, Australia
\end{abstract}

\begin{abstract}
The effects of bone anabolic agents such as bone morphogenetic proteins (BMPs) have the potential to be augmented by co-treatment with an anti-catabolic such as a bisphosphonate. We hypothesised that the effects of bisphosphonates on BMP-induced bone anabolism would be dose dependent, and we aimed to test this in a small animal model. Agents were delivered locally using a biodegradable poly-D, L-lactic-acid (PDLLA) polymer delivery system. Recombinant human BMP-7 (25 $\mu \mathrm{g})$ was tested with a range of doses of the bisphosphonate pamidronate $(0.02 \mathrm{mg}, 0.2 \mathrm{mg}$ and $2 \mathrm{mg}$ local PAM; 0.3 $\mathrm{mg} / \mathrm{kg}$ and $3 \mathrm{mg} / \mathrm{kg}$ thrice-weekly systemic PAM) versus BMP-7 alone. Polymer pellets were surgically implanted in the hind limbs of female C57BL6/J mice (8-10 week) and ectopic bone nodules were harvested at 3 and 8 weeks post-operatively. At 3 weeks, local low dose PAM (0.02 $\mathrm{mg}$ ) induced a 102\% increase in rhBMP-7 induced bone volume $(p<0.01)$ as measured by microCT, and this was comparable to systemic PAM $(0.3 \mathrm{mg} / \mathrm{kg}$ thrice-weekly). In contrast, local high dose PAM (2 mg) resulted in a 97\% decrease in bone volume $(p<0.01)$. Radiography and histology indicated that the polymer vehicle was still largely present at 8 weeks indicating inefficient biodegradation. This is the first study to validate the utility of local codelivery of $\mathrm{BMP} /$ bisphosphonate via biodegradable polymer and supports the continued refinement of more advanced bioresorbable delivery systems for clinical applications.
\end{abstract}

Keywords: Anabolism, catabolism, bone tissue engineering, bone morphogenetic protein (BMP), bisphosphonate.

*Address for correspondence:

Nicole Y.C. Yu / Aaron Schindeler

The Children's Hospital at Westmead

Orthopaedic Research and Biotechnology Unit

Locked Bag 4001

Westmead, Sydney, NSW 2145, Australia

E-mail: nicole.yu@sydney.edu.au aaron.schindeler@sydney.edu.au

\section{Introduction}

Bone morphogenetic proteins (BMPs) produced via recombinant gene technology (rhBMP-2 and rhBMP-7/ OP-1) have been clinically used for spinal fusion and the repair of non-unions (Friedlaender et al., 2001; Govender et al., 2002; Vaccaro et al., 2003; Mulconrey et al., 2008). BMPs exert their effects on cells via binding to specific membrane receptors. The binding of BMPs to type-I and type-II membrane serine/threonine receptors, stimulates the initiation of an intracellular signalling cascade (Dimitriou and Giannoudis, 2005; Termaat et al., 2005). BMPs are able to strongly promote the recruitment and differentiation of mesenchymal progenitor cells into boneforming osteoblasts (Okamoto et al., 2006). In an orthopaedic context, this can facilitate the generation of large amounts of new bone. However, BMPs are also able to directly and indirectly induce osteoclast differentiation, and mature osteoclast function and survival, leading to premature or excessive bone resorption (Itoh et al., 2001; Kaneko et al., 2000; Katagiri and Takahashi, 2002). Bone resorption may be additionally problematic in the context of bone tissue engineering, where the new bone is often mechanically unloaded (Cooley et al., 2005; Seeherman et al., 2010). Consequently, one approach to maximize the effects of BMPs is to systemically administer an antiresorptive (such as a bisphosphonate), and this has been effective in small animal critical-size bone defect repair (Seeherman et al., 1998; Seeherman et al., 2000; Bouxsein et al., 2001; Little et al., 2005), and bone remodelling in bone graft chambers (Harding et al., 2008; Tägil et al., 2006), as well as non-human primate bone defects (Seeherman et al., 2001). Bisphosphonates accumulate at sites of bone mineral deposition, and in particular in regions of high bone turnover. They are released during bone resorption and internalized by osteoclasts leading to inhibition of osteoclast activity and/or osteoclast apoptosis. Consequently, bisphosphonates are potent inhibitors of osteoclast mediated bone resorption (Rogers, 2003). The mechanism of action differs between the type of bisphosphonates. Non-nitrogen containingbisphosphonates are metabolized to give toxic by-products that induce cellular apoptosis. In contrast, nitrogen containing-bisphosphonates bind and inhibit the enzyme farnesyl diphosphate synthase, which in turn leads to decreased cellular function and apoptosis (Luckman et al., 1998; Coxon et al., 2000; Green, 2005). 
Due to the potent capacity of BMPs to produce bone in a range of tissues, systemic approaches are not viable. Any system for BMP local delivery should take into account its short biological half-life and rapid local clearance in order to maximise new bone (Ruhé et al., 2006). Animal-derived collagen has historically been and remains the primary BMP carrier material for clinical defects. While collagen is a natural component of the skeleton, as a BMP carrier material it is has certain limitations. Collagen has relatively poor BMP retention (Kato et al., 2006b), leading to a requirement for higher BMP drug concentrations and thus a higher cost (Geesink et al., 1999). There are also potential risks of disease transfer from animal-derived collagen (DeLustro et al., 1990), as well as an immunogenic response from the host (Olsen et al., 2003). Collagen also has poor mechanical strength and can therefore be difficult to shape (Friess, 1998; Yang et al., 2001).

To overcome these shortcomings, synthetic biodegradable polymers can be considered as a potential alternative. Poly-D,L-lactic-acid (PDLLA) is a common and inexpensive polymer that has been used as an implant coating material for growth factor delivery (Schmidmaier et al., 2001; Schmidmaier et al., 2004), and for BMP delivery in bone tissue engineering and defect repair (Zegzula et al., 1997; Saito et al., 1999; Saito et al., 2001a; Saito et al., 2001b; Saito and Takaoka, 2003; Saito et al., 2003; Kato et al., 2006a; Kato et al., 2006b; Yu et al., 2010). PDLLA also has the capacity to act as a local delivery system for bisphosphonates (Choi et al., 2007; Greiner et al., 2007a; Greiner et al., 2007b; Greiner et al., 2008). A local approach could overcome some of the adverse side-effects associated with systemic bisphosphonate dosing including stomach ulceration, low bioavailability of oral drugs and flu-like symptoms (Thiébaud et al., 1997; Mönkkönen et al., 1998). Renal failure and osteonecrosis of the jaw are rare but more severe adverse effects associated with systemic bisphosphonate use (Marx, 2005). Nevertheless, high doses of local bisphosphonate (2-3 mg pamidronate) in a poly-L-lactideco-glycolide (PLGA) polymer have been reported to impair bone formation in a calvarial defect model (Choi et al., 2007). We hypothesised that the capacity of locally delivered bisphosphonate to aid or inhibit bone formation may be dose dependent. We speculated that a range of local bisphosphonate doses could be used to reveal both effects.

In this study we used a simple, well-described in vivo model of intramuscular BMP-induced bone formation. BMP-induced nodule formation has been previously described using a range of delivery systems including collagen, carboxymethylcellulose, and synthetic polymers (Saito et al., 2001a; Little et al., 2005; Saito et al., 2005; Kato et al., 2006b; Schindeler et al., 2008). We selected a static dose of recombinant human BMP-7 (25 $\mu \mathrm{g}$ rhBMP7) and a variable dose of local pamidronate $(0 \mathrm{mg}, 0.02$ $\mathrm{mg}, 0.2 \mathrm{mg}$ and $2 \mathrm{mg}$ ). Control groups where pamidronate was administered systemically $(0.3 \mathrm{mg} / \mathrm{kg}$ and $3 \mathrm{mg} / \mathrm{kg}$ thrice-weekly) were also tested. The aim of this study was to examine in principle whether local bisphosphonate dosing has the potential to augment BMP-induced bone anabolism, and we hypothesised that this would occur only within a specific dose range.

\section{Materials and Methodology}

\section{Pharmaceuticals}

Purified rhBMP-7 was produced and donated by Stryker Biotechnology (Hopkinton, MA, USA) and supplied as a lyophilized protein in lactose monohydrate carrier $(0.01 \%$ trifluoroacetic acid, $\mathrm{pH} 3.3$ ). Disodium pamidronate (PAM) powder (Cipla, Mumbai, India) was used for local delivery. A solution of Pamisol ${ }^{\circledR}$ (Mayne Pharma, Mulgrave, VIC, Australia), i.e., disodium pamidronate in mannitol, phosphoric acid, and sodium hydroxide in water $(\mathrm{pH}$ 6.5) was used for systemic delivery, diluted with saline as necessary.

\section{Polymer carrier materials and manufacturing}

Poly-D,L-lactic-acid (PDLLA) biodegradable polymer (inherent viscosity 0.55-0.75, average $\mathrm{M}_{\mathrm{w}}$ 75,000-120,000; Sigma-Aldrich, Sydney, Australia) and organic solvent, ethyl acetate (analytic reagent grade, Chem Supply, Gillman, South Australia) were used for the fabrication of biodegradable polymer carrier. PDLLA pellets each containing $25 \mu \mathrm{g}$ rhBMP-7 and $0 \mathrm{mg}, 0.02 \mathrm{mg}, 0.2 \mathrm{mg}$, or $2 \mathrm{mg}$ PAM were prepared by the solvent casting method. Briefly, PDLLA was solubilised in ethyl acetate solvent by vortex and water bath sonication. Two drug solutions were prepared by mixing rhBMP-7 or PAM in ethyl acetate. The polymer and drug solutions were combined by vortexing and sonication in a water bath $\left(25^{\circ} \mathrm{C}\right)$. The solvent was removed by vacuum evaporation resulting in a semi-solid polymer. A compressor system modified from $0.3 \mathrm{ml}$ insulin syringes (B. Braun Medical Industries, Penang, Malaysia) was used to compress the semi-solid polymer into disks (average diameter $2.8 \mathrm{~mm}$ and height $1.6 \mathrm{~mm}$ ). Following compression, the residual solvent was removed by vacuum evaporation (Fig. 1).

\section{Animal care}

Female C57BL6/J wild type mice (8-10 week, average weight $18 \mathrm{~g}$ ) were housed in autoclavable polypropylene solid boxes with stainless steel lids and polycarbonate water bottles with food and mouse chow supplied ad libitum. Ethics approval was obtained for all procedures from the Westmead Hospital Animal Ethics Committee.

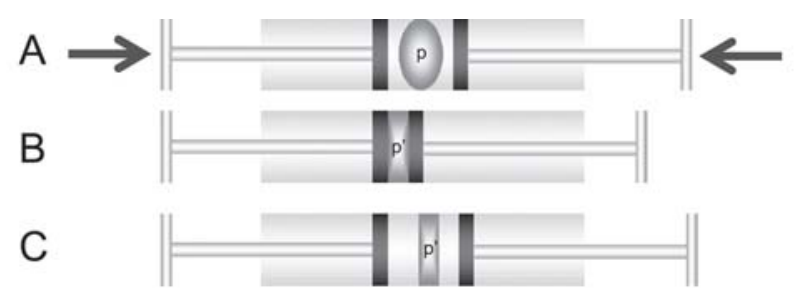

Fig. 1. Double-plunger syringe system. (A) Semi-solid polymer (p) is placed in syringe barrel and $(\mathbf{B})$ compressed between two syringe plungers, $(\mathbf{C})$ leaving a polymer pellet (p'). 


\section{Surgical model}

Ectopic bone formation was induced in a quadriceps muscle pouch following surgical implantation of rhBMP7-loaded PDLLA carrier. The surgical model was based on previously published methods where rhBMP-2 was delivered in a carboxymethylcellulose carrier (Schindeler et al., 2008). In brief, anaesthesia was induced and maintained using inhaled isofluorane. The operative site was trimmed and prepared with povidone-iodine. A muscle pouch was created using a scalpel in the right hind limb, in line with the femur. The polymer pellet was inserted and the muscle and skin closed using a 5-0 Vicryl suture (Ethicon, Somerville, NJ, USA). Following surgery, animals were recovered on a heated pad and placed in recovery cages. Post-operative pain was managed with subcutaneously injected buprenorphine $(0.05 \mathrm{mg} / \mathrm{kg})$ and dehydration was managed by saline injection, as required. Animals were monitored by weekly weighing.

\section{Experimental design}

In the context of the rhBMP-7 induced bone formation model, the effects of different PAM doses and local versus systemic delivery were compared. Mice were assigned to each group: rhBMP-7 only controls ( $\mathrm{n}=9$ ); rhBMP-7 with $0.02 \mathrm{mg}, 0.2 \mathrm{mg}$, or $2 \mathrm{mg}$ local PAM ( $\mathrm{n}=9$ each); and rhBMP-7 with $0.3 \mathrm{mg} / \mathrm{kg} / \mathrm{dose}$ or $3 \mathrm{mg} / \mathrm{kg} /$ dose systemic PAM ( $\mathrm{n}=8$ each). Mice receiving systemic PAM were dosed subcutaneously thrice weekly from day 2 to day 19 to ensure that all forming rhBMP-induced bone could be exposed to bisphosphonate (Schindeler et al., 2008). The equivalent 8 total PAM doses were $0.048 \mathrm{mg}$ (low dose PAM group) and $0.48 \mathrm{mg}$ (high dose PAM group). Animals were euthanized using carbon dioxide at 3 weeks or 8 weeks post-operatively. Whole hind limbs were harvested post-mortem, fixed in 4\% paraformaldehyde, and stored in $70 \%$ alcohol for radiographic and histological analysis. Samples were excluded for those specimens where the ectopic bone had provoked a periosteal response and fused with the femora. The numbers for all inclusions are summarised in Table 1.

A second experiment was subsequently performed with an extended end point of 8 weeks. Animals in the systemic PAM groups were again dosed subcutaneously thrice weekly from day 2 to day 21 . The equivalent total PAM doses for the 8 week systemic groups were $0.054 \mathrm{mg}$ (low dose PAM group) and $0.54 \mathrm{mg}$ (high dose PAM group). Compared to the 3 week study, animals in the 8 week study received one additional PAM dose (at exactly 3 weeks).
The additional PAM dose in the 8 week study allowed retention of the bone formed up to 3 weeks. In the 3 week study, no additional PAM dose was required, since animals were sacrificed on the day the last dose was due.

\section{Radiographic analysis}

The placement of the ectopic bone nodules relative to the femur was determined by radiography using a digital Xray machine (Faxitron X-rayCorp, Wheeling, IL, USA) of whole hind limbs $(27 \mathrm{kV}, \times 2$ magnification $)$. Ectopic bone samples and the surrounding soft tissue was further isolated and radiographed individually $(27 \mathrm{kV}, \times 3$ magnification). At this stage samples were excluded where the ectopic bone had fused with the femur, or had migrated out of the muscle pouch so that negligible bone had formed.

The remaining samples were examined by microcomputed tomography ( $\mu \mathrm{CT})$ scanning using a SkyScan 1174 compact $\mu$ CT scanner (SkyScan, Kontich, Belgium). The primary outcome measure for the study was total bone volume of the entire ectopic bone nodule. Samples were scanned in $70 \%$ ethanol at $8.7 \mu \mathrm{m}$ pixel resolution, 0.5 $\mathrm{mm}$ aluminium filter, $50 \mathrm{kV}$ X-ray tube voltage and 800 $\mu \mathrm{A}$ tube electric current. The images were reconstructed using NRecon, version 1.5.1.5 (SkyScan). Bone volume $\left(\mathrm{BV}, \mathrm{mm}^{3}\right)$ of the entire ectopic bone nodule was analysed with CTAnalyser software, version 1.9.2.3 (SkyScan). A global threshold representing bone (44-255) was defined following analysis of consecutive two-dimensional slices of bone samples on CTAnalyser software. Representative three-dimensional bone pellets were reconstructed with transaxial slices (100 slices) from the pellet's mid-section, using CTVol Realistic Visualisation software version 2.1.0.0 (SkyScan). Representative ectopic bone samples from each group were selected as having a BV closest to the group's mean.

\section{Statistical analysis}

For statistical analysis of in vivo data, group sizes $<10$ necessitated non-parametric statistical tests. Kruskal Wallis and Mann Whitney U tests were performed using SPSS Statistics version 17 (SPSS, Chicago, IL, USA). Statistical significance was set at $\alpha<0.05$.

\section{Histological analysis}

For paraffin histology, samples were decalcified and embedded in paraffin blocks. $0.5 \mathrm{~mm}$-thick sections were cut using a Leica RM 2155 Microtome (Leica Microsystems, Wetzlar, Germany). Sections were stained

Table 1. Test groups

\begin{tabular}{|c|c|c|c|c|c|}
\hline Group & $\begin{array}{c}\text { BMP-7 } \\
\text { (local delivery } \\
\text { via pellet) }\end{array}$ & $\begin{array}{c}\text { PAM } \\
\text { (local delivery } \\
\text { via pellet) }\end{array}$ & $\begin{array}{c}\text { PAM } \\
\text { (systemic via } \\
\text { injection) }\end{array}$ & $\begin{array}{c}\text { N } \\
\text { (3 week) }\end{array}$ & $\begin{array}{c}\text { N } \\
\text { (8 week) }\end{array}$ \\
\hline 1 & $25 \mu \mathrm{g}$ & $0 \mathrm{mg}$ & $0 \mathrm{mg}$ & 8 & 9 \\
\hline 2 & $25 \mu \mathrm{g}$ & $0.02 \mathrm{mg}$ & $0 \mathrm{mg}$ & 9 & 8 \\
\hline 3 & $25 \mu \mathrm{g}$ & $0.2 \mathrm{mg}$ & $0 \mathrm{mg}$ & 9 & 8 \\
\hline 4 & $25 \mu \mathrm{g}$ & $2.0 \mathrm{mg}$ & $0 \mathrm{mg}$ & 9 & 9 \\
\hline 5 & $25 \mu \mathrm{g}$ & $0 \mathrm{mg}$ & $0.3 \mathrm{mg} / \mathrm{kg}$ & 7 & 8 \\
\hline 6 & $25 \mu \mathrm{g}$ & $0 \mathrm{mg}$ & $3 \mathrm{mg} / \mathrm{kg}$ & 7 & 7 \\
\hline
\end{tabular}



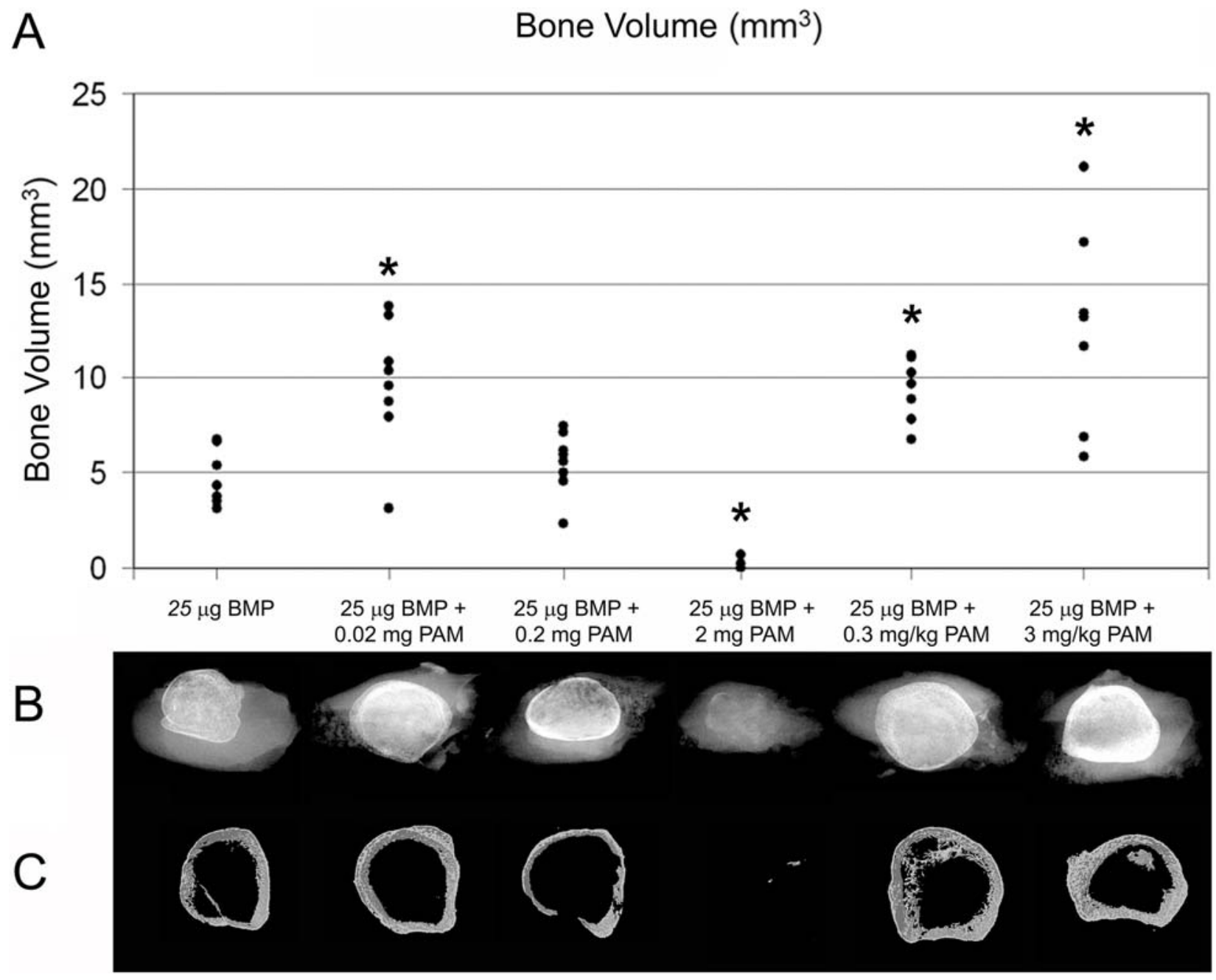

Fig. 2. Bone formation following 3 week implant insertion in muscle pouch as assessed by quantification bone volume with representative $\mathrm{x}$-ray and $\mu \mathrm{CT}$ images. (A) Bone volume $\left(\mathrm{mm}^{3}\right)$ of ectopic bone nodules was measured by $\mu \mathrm{CT}$ of dissected specimens. rhBMP-7 induced bone formation was significantly increased by co-delivery of local $0.02 \mathrm{mg}$ PAM (102\%), systemic PAM $0.3 \mathrm{mg} / \mathrm{kg}(97 \%)$ and $3 \mathrm{mg} / \mathrm{kg}(169 \%)$. No significant increase in bone formation was found in the local $0.2 \mathrm{mg}$ PAM group. Local $2 \mathrm{mg}$ PAM reduced bone formation (97\%). Statistical significance was calculated versus rhBMP-7 alone $(*=p<0.01)$. (B) X-ray images and $(\mathbf{C})$ three-dimensional $\mu C T$ reconstructions of entire ectopic bone nodules showing bone formation in all groups except rhBMP-7/local $2 \mathrm{mg}$ PAM.

with Haematoxylin \& Eosin (H \& E), Alcian blue \& Picrosirius red for bone and cartilage, and Tartrate Resistant Acid Phosphatase (TRAP) for osteoclasts. Stained sections were scanned with ScanScope digital slide scanner (Aperio Technologies, Vista, CA, USA), and images were captured with ImageScope (Aperio Technologies).

\section{Results}

Local low dose and systemic PAM increase rhBMP-7 induced bone formation

Pellets containing rhBMP-7 with and without PAM were surgically implanted into C57B6/J mice. Three mice were excluded due to pellet misplacement (operatively) or migration (post-operatively) as per Table 1. Specimens were harvested after 3 weeks, during which time some mice received systemic PAM injections. All samples were subjected to X-ray and $\mu \mathrm{CT}$ scanning followed by histological processing. The primary outcome measure for the study was total bone volume $\left(\mathrm{BV}, \mathrm{mm}^{3}\right)$ of the entire ectopic bone nodule, as quantified by $\mu \mathrm{CT}$ (Fig. 2A).

All treatment groups were compared to the control group of rhBMP-7 alone. BV was increased by $102 \%$ with co-delivery of low $0.02 \mathrm{mg}$ local PAM $(p<0.01)$ compared to controls. This dosage effectively doubled the amount of net bone at 3 weeks. There was a $14 \%$ increase in BV in the medium $0.2 \mathrm{mg}$ local PAM that was not significant $(p<0.6)$. The high $2 \mathrm{mg}$ local PAM treatment dramatically impaired bone formation, reducing the total BV by $97 \%$ $(p<0.01)$. In this high dose group many specimens had absolutely no bone as visualised by X-ray or detected by $\mu \mathrm{CT}$ with standard thresholds for bone.

Both $0.3 \mathrm{mg} / \mathrm{kg}$ and $3 \mathrm{mg} / \mathrm{kg}$ systemic PAM groups showed considerable increases in BV. Compared to 

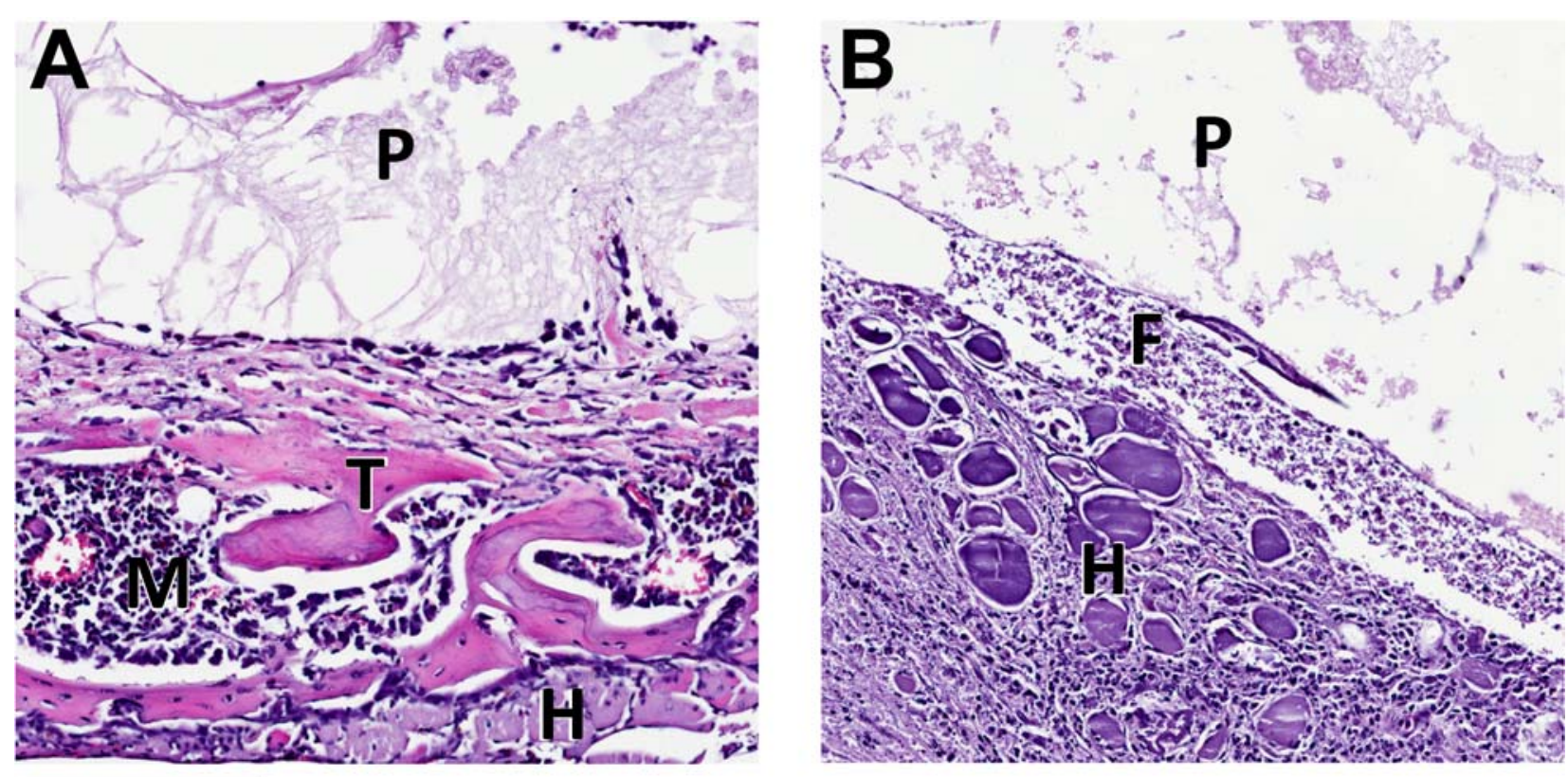

Fig. 3. Representative histological sections of interfaces of ectopic bone formed following 3 weeks intramuscular implantation. (A) BMP control, and (B) Local high PAM dose (2 mg). H \& E staining showed large amounts of residual polymer $(\mathrm{P})$ surrounded by haematopoietic marrow $(\mathrm{M})$ and bony trabeculae $(\mathrm{T})$, which was encapsulated by a host muscular tissue region $(\mathrm{H})$. Bone formation was consistently found in all groups, except local high PAM (2 $\mathrm{mg}$ ), where sporadic or no bone formation was observed. Polymer was mainly surrounded by fibrous tissue (F). (Scale bar $=200 \mu \mathrm{m})$
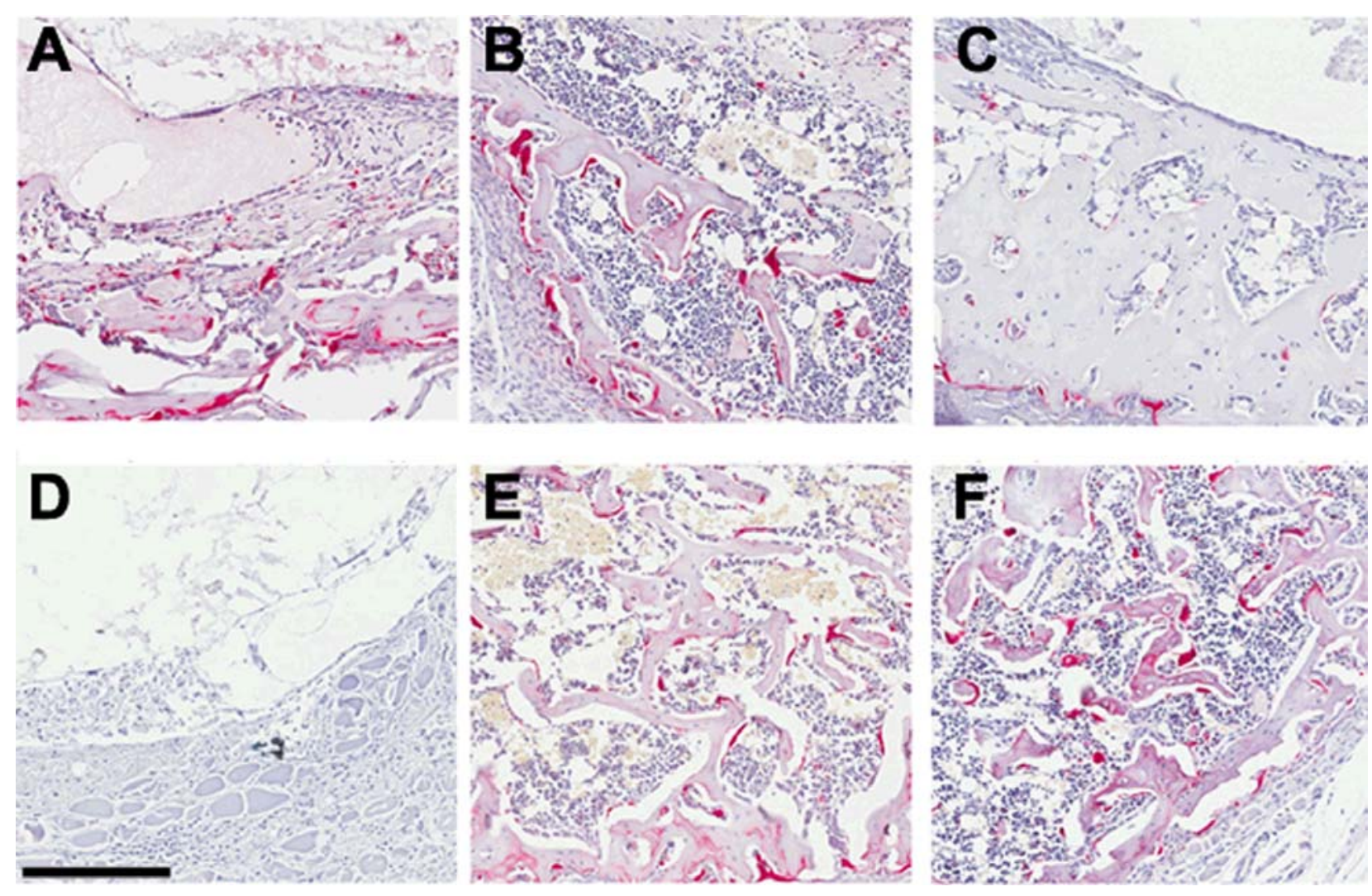

Fig. 4. Representative Tartrate Resistant Acid Phosphatase (TRAP)-stained histological sections of osteoclasts in trabecular-like structure of ectopic bone formed following 3 weeks intramuscular implantation. (A) BMP control, (B) BMP + local low PAM (0.02 mg), (C) BMP + local medium PAM (0.2 mg), (D) BMP + local high PAM (2 mg), (E) BMP + low systemic PAM $(0.3 \mathrm{mg} / \mathrm{kg})$, and (F) BMP + high systemic PAM (3 mg/kg). Compared to BMP control, local low and medium PAM groups (B and $\mathbf{C})$, resulted in lower osteoclast positive staining at the bone/ pellet region compared to bone/host tissue region. In addition, local medium PAM dose (0.2 $\mathrm{mg})$ group (C) resulted in lower overall osteoclast positive staining in the trabecular bone sheath. (Scale bar $=200 \mu \mathrm{m})$ 


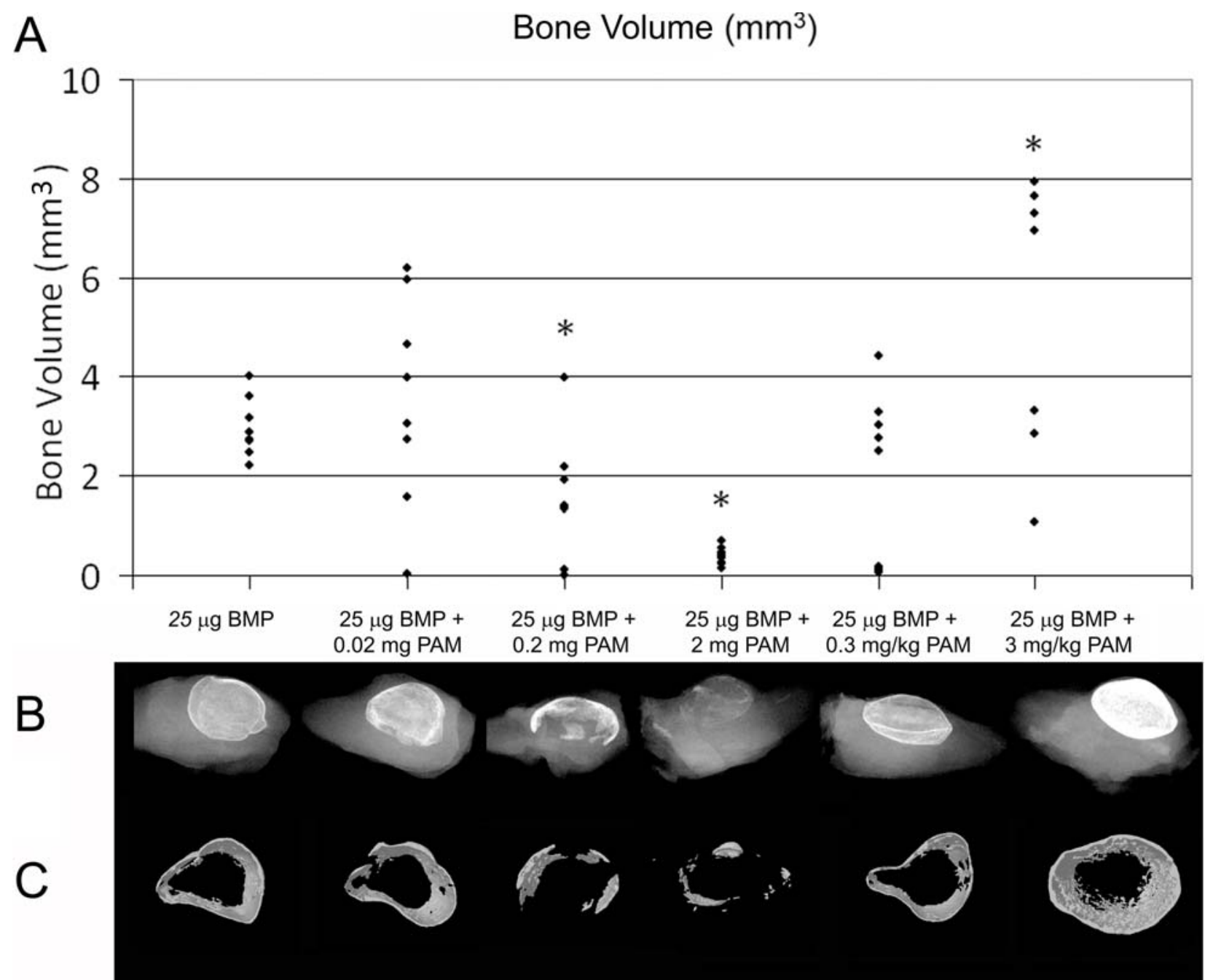

Fig. 5. Bone formation following 8 week implant insertion in muscle pouch as assessed by quantification bone volume with representative $\mathrm{x}$-ray and $\mu \mathrm{CT}$ images. (A) Bone volume $\left(\mathrm{mm}^{3}\right)$ of ectopic bone nodules was measured by $\mu \mathrm{CT}$ of dissected specimens. At 8 weeks the rhBMP-7 induced bone formation no longer significantly increased by co-delivery of local $0.02 \mathrm{mg}$ PAM or systemic PAM $0.3 \mathrm{mg} / \mathrm{kg}$, although systemic PAM $0.3 \mathrm{mg} / \mathrm{kg}$ still showed a difference (79\%). Local $0.2 \mathrm{mg}$ and $2 \mathrm{mg}$ PAM reduced bone formation by $54 \%$ and $87 \%$, respectively. Statistical significance was calculated versus rhBMP-7 alone $(*=p<0.01)$. (B) X-ray images and (C) three-dimensional $\mu C T$ reconstructions of entire ectopic bone nodules.

controls, the $0.3 \mathrm{mg} / \mathrm{kg}$ systemic PAM increased BV by $97 \%(p<0.01)$, which was comparable to the $102 \%$ improvement seen with local low dose PAM $(0.02 \mathrm{mg})$. The $3 \mathrm{mg} / \mathrm{kg}$ systemic PAM increased BV by $169 \%$ $(p<0.01)$.

As a secondary outcome, the architecture of the ectopic bone nodules was examined by radiography (Fig. 2B) and $\mu \mathrm{CT}$ (Fig. 2C). Three-dimensional $\mu \mathrm{CT}$ reconstructions of transaxial mid-sections of bone nodule were generated. A trabecular-like bone structure was observed around a hollow core that was speculated to contain residual polymer. Due to the low material density of PDLLA, it was not represented in the reconstruction.

Increased thickness of trabecular-like bone structure was observed in the low $0.02 \mathrm{mg}$ local PAM group, and both systemic PAM groups. Medium $0.2 \mathrm{mg}$ local PAM did not increase bone sheath thickness of rhBMP-7induced bone, and high $2 \mathrm{mg}$ local PAM led to inconsistent and small, abnormally shaped bone nodules.
Biodegradation of solvent-cast rhBMP-7/PDLLA polymer at 3 and 8 weeks

Histological analysis confirmed that the majority of the biodegradable polymer pellet remained after 3 weeks postimplantation.

In most groups, the residual pellet was surrounded by hematopoietic marrow and bony trabeculae (Fig. 3A). Codelivery with high $2 \mathrm{mg}$ local PAM led to abundant fibrous tissue formation and little bone (Fig. 3B). Comparing osteoclast positive staining in the bony trabeculae of BMP control with co-treatment groups (Fig. 4A-F), lower osteoclast positive staining was found in bony trabeculae closer to polymer pellet of local PAM low and medium dose (Fig. 4B and C). In addition, medium $0.2 \mathrm{mg}$ local PAM dosing resulted in lower overall osteoclast-positive staining in the trabecular bone sheath.

To determine whether the residual PDLLA pellet would degrade further over time and whether it could continue to affect bone formation and resorption, a second 

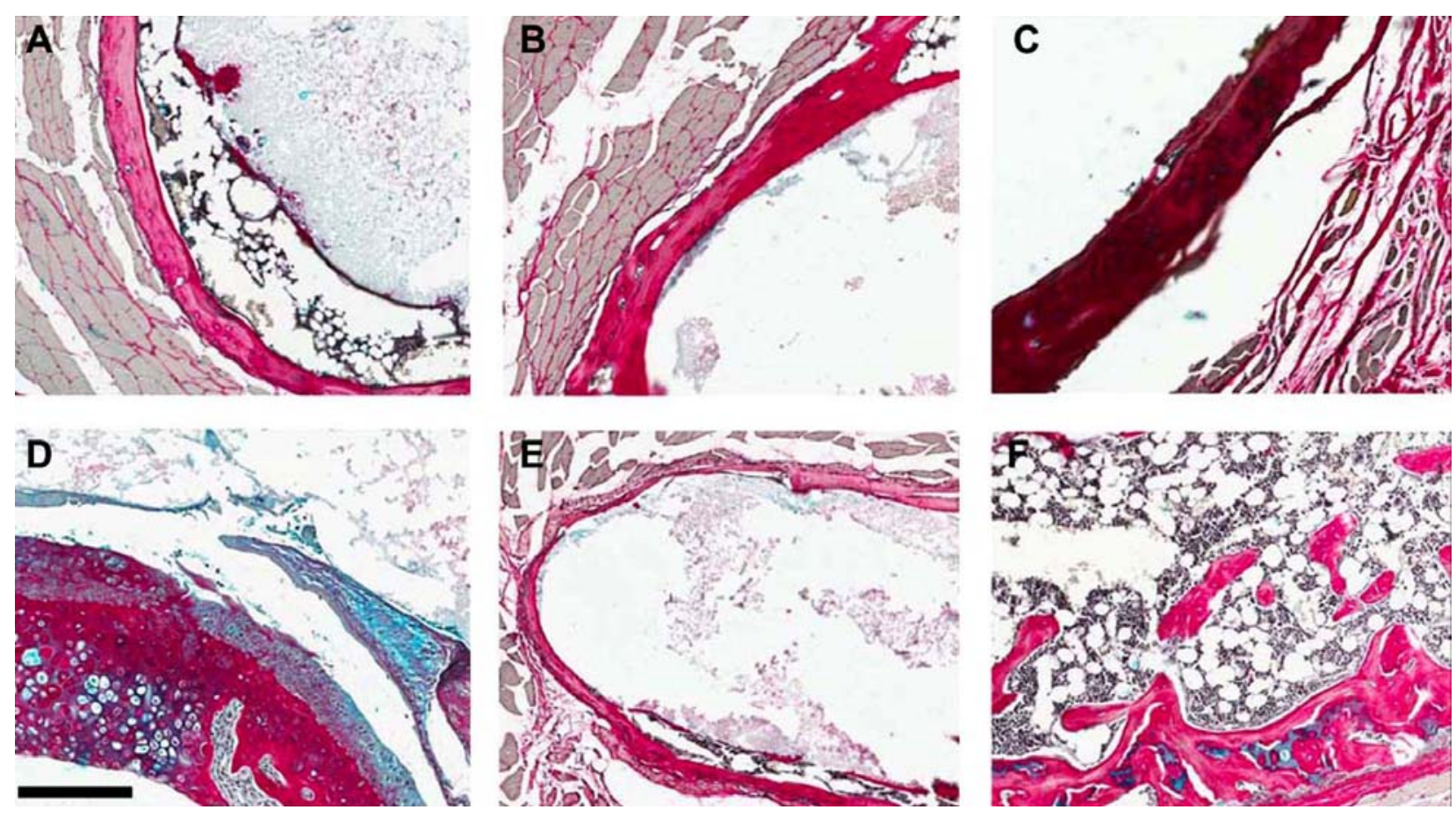

Fig. 6. Representative histological sections of ectopic bone formed following 8 weeks intramuscular implantation. At the 8 week time point, PDLLA polymer was still present in the core of implanted ectopic bone nodules. (A) rhBMP-7 control, (B) rhBMP-7 with local low PAM (0.02 mg), (C) rhBMP-7 with local medium PAM (0.2 mg), (D) rhBMP-7 with local high PAM (2 mg), (E) rhBMP-7 with low systemic PAM $(0.3 \mathrm{mg} / \mathrm{kg})$, and (F) rhBMP-7 with high systemic PAM (3 mg/kg). Alcian blue/Picrosirius red staining indicated remaining islands of cartilage in the bone formed by rhBMP-7 with local $2 \mathrm{mg}$ PAM. (Scale bar $=200 \mu \mathrm{m}$ ).

experiment with a later time point of 8 weeks was instigated. In this study, four mice were excluded at the 8 week endpoint due to pellet misplacement or ectopic bone fusing with the femur. Of the exclusions, one specimen was excluded from each of the control, local low PAM (0.02 mg), local medium PAM (0.2 mg), and high systemic PAM (3 mg/kg).

The results of this study indicated that the effects of bisphosphonate dosing did not persist significantly at this later time point. $\mu \mathrm{CT}$ analysis of $\mathrm{BV}$ for the entire ectopic bone nodule showed the local low PAM $(0.02 \mathrm{mg})$ and systemic $0.3 \mathrm{mg} / \mathrm{kg}$ PAM no longer showed a significant increase, compared to controls. The local medium $0.2 \mathrm{mg}$ PAM and local high $2 \mathrm{mg}$ PAM were significantly reduced versus controls ( $54 \%$ and $87 \%$ decreases; $p<0.02, p<0.01$ respectively). The only group that showed a persistent increase was the high $3 \mathrm{mg} / \mathrm{kg}$ systemic dose PAM (79\% increase, $p<0.02$ ) (Fig. 5).

Both radiographic and histology revealed the majority of the biodegradable polymer pellet still remained at 8 weeks. The PDLLA was encapsulated in a bony cortex, which may affect the degradation rate. Alcian blue \& Picrosirius red staining of the control group indicated no presence of cartilage and a thin bone sheath surrounding the pellet. In the high local PAM (2 mg) group, cartilage remnants enveloped in bone (primary spongiosa) were present in the minimal bone that had formed. High systemic PAM ( $3 \mathrm{mg} / \mathrm{kg}$ ) co-treatment led to thicker bone sheath with trabecular-like features although some islands of cartilage were present in the bony trabeculae (Fig. 6).

\section{Discussion}

To our knowledge, this is the first study to demonstrate that BMP and bisphosphonate treatment can be synergistic when co-delivered locally through a polymer scaffold. We have previously described the concept of anabolic/anticatabolic treatment for orthopaedics with a focus on systemic bisphosphonate treatments and these principles have now been translated to the field of bone tissue engineering (Little et al., 2005; Little et al., 2007).

A number of prior studies have examined the interactions between BMPs and systemic bisphosphonates in animal models (Seeherman et al., 2001; Little et al., 2005; Tägil et al., 2006; Harding et al., 2008). In the earliest of these studies, rhBMP-7/carboxymethylcellulose (OP1) was used in combination with the bisphosphonate ZoledronicAcid (ZA) to stimulate healing in a rat criticalsized femoral defect. Fracture callus size and strength were greatly improved by a single systemic dose of ZA $(0.1$ $\mathrm{mg} / \mathrm{kg}$, immediately post-operatively, or 2 weeks postoperatively) (Little et al., 2005). Analogous results were obtained using a rabbit conduction bone graft chamber model, where bony ingrowth into an isolated chamber was quantified. Again, a combination of local rhBMP-7 and bolus systemic ZA $(0.1 \mathrm{mg} / \mathrm{kg})$ increased bone ingrowth and net bone formation, compared to controls. In the context of an unloaded chamber, intrinsic catabolic pressures were high and the bisphosphonate-free controls showed tremendous resorption within the same time period (Tägil et al., 2006; Harding et al., 2008). Similar findings 
have been seen with other bisphosphonates and in higher vertebrates. For example, systemic ibandronate $(0.15 \mathrm{mg} /$ $\mathrm{kg}$, monthly from 1 month pre-op until 6 months post-op) eliminated transient bone resorption of rhBMP-2/ACSinduced bone in the distal femoral core defect of nonhuman primates (Seeherman et al., 2001). Consistent with these previous studies, we found that systemic doses of PAM $(0.3 \mathrm{mg} / \mathrm{kg}$ and $3 \mathrm{mg} / \mathrm{kg})$ increased the net bone produced by rhBMP-7 pellet implantation.

One important aim of this study was to compare the efficacy of local versus systemic bisphosphonate dosing. As previously noted, the complications associated with systemic bisphosphonates make local dosing an appealing alternative. Our data shows that local dosing of $0.02 \mathrm{mg}$ PAM and $0.2 \mathrm{mg}$ PAM did not impair bone formation compared to controls. The $0.02 \mathrm{mg}$ PAM dose led to increased net bone at the 3 week study end point. These findings indicate that local bisphosphonate can be effective in retaining rhBMP-induced bone in the short term.

Previous attempts to deliver bisphosphonates locally have not yielded favourable outcomes. Choi et al. found that high doses (2 $\mathrm{mg}$ and $3 \mathrm{mg}$ ) of pamidronate (PAM) delivered locally via polymer impaired bone healing rat calvarial defect (Choi et al., 2007). Local PAM was also found to impair an implant fixation model where $0.45 \mathrm{mg}$ rhBMP-2 and bone allograft were treated with $9 \mathrm{mg} / \mathrm{ml}$ PAM (Baas et al., 2008). In both cases we speculated that this impairment may be due to the PAM dose, and that lower doses may have less adverse and possibly beneficial effects. In our model system the highest local dose of 2 mg PAM severely impaired ectopic bone formation and erratic bone formation ensued.

Data from Jakobsen et al. similarly advocates a conservative approach to bisphosphonate dosing in the context of local treatment. In a canine titanium implant fixation model, morselised bone graft soaked in high dose alendronate significantly impaired implant fixation, inhibited new bone formation and reduced resorption of the graft material (Jakobsen et al., 2007). A subsequent study using a range of ZoledronicAcid (ZA) doses showed that implant fixation in the canine model could be increased with low ZA dose $(0.005 \mathrm{mg} / \mathrm{mL})$ but that the highest ZA dose $(0.5 \mathrm{mg} / \mathrm{mL})$ decreased bone formation (Jakobsen et al., 2010). These findings are consistent with our data showing an optimal dose window for bisphosphonate synergy with an anabolic bone stimulus.

The concept of anabolic and anti-catabolic synergy has gained additional support from alternative non-polymeric delivery systems. When used to supplement bone graft, rhBMP-7 and clodronate were found to increase bone ingrowth (Jeppsson et al., 2003). In a later study, the dosedependent effect of local clodronate was trialled, and although high doses did not impair bone formation, their doses were still significantly less $(21 \mu \mathrm{g}$ per graft) than the doses of PAM administered in our study (Agholme and Aspenberg, 2009). Chen et al. used a ceramic $\beta$ tricalcium phosphate scaffold to co-deliver rhBMP-2 and the bisphosphonate minodronate. Addition of the bisphosphonate prevented bone loss over 4 weeks and led to a net increase in bone density and mechanical strength over rhBMP-2 alone (Chen et al., 2004). In a follow-up study, the ectopic bone was successfully used as a graft material in a femoral muscle pedical flap model (Chen et al., 2006).

This model of ectopic bone formation was used as an assay system for rapid screening of local drug dosing, as has been previously described (Schindeler et al., 2010). While this system is a simple and reproducible method for generating new bone, it has several important limitations. It is able to produce a dense cortical-like bone sheath with internal hematopoietic marrow and bony trabeculae, as seen by histology, but PDLLA polymer degrades slowly and is still present even after 8 weeks. The retention of significant amounts of polymer even at the later time point has lead us to speculate that an alternative faster degrading polymer would be advantageous. Another limitation is that it relies on inducible osteoprogenitors within the bone marrow compartment, which may or may not behave in the same manner as committed osteoprogenitors from the periosteum or endosteal space. Ectopic bone induced by rhBMP in an intramuscular site has been shown as suitable graft material for bone defect repair (Chen et al., 2006; Inoda et al., 2007), therefore we selected this model to test our anabolic/anti-catabolic concept. More advanced surgical models will be need to be applied to confirm the utility of biodegradable polymeric scaffolds to co-deliver BMP and bisphosphonate for the healing of critical defects.

In conclusion, despite the recalcitrant polymer degradation, this study is the first to demonstrate a dosedependent response for local bisphosphonate co-delivered with BMP via biodegradable polymer. As per the diamond concept for bone tissue engineering, mechanical stimulation is essential for optimal bone retention (Giannoudis et al., 2007) and stress shielding can lead to premature bone resorption. This study shows proof-ofconcept that with appropriate dosing, local bisphosphonate may have the potential to improve BMP-induced bone and thus may have translational applications for maximising bone formation in mechanically unfavourable environments.

\section{Acknowledgments}

The recombinant human rhBMP-7 (rhBMP-7) was generously donated by Stryker Biotechnology. The project was funded by the Australian Orthopaedic Research Foundation. Nicole Y. C. Yu was supported by the Australian National Health \& Medical Research Council (NHMRC) Biomedical Postgraduate Research Scholarship. Dr. Aaron Schindeler was supported by a Children's Tumor Foundation Young Investigator Award.

\section{References}

Agholme F, Aspenberg P (2009) Experimental results of combining bisphosphonates with allograft in a rat model. J Bone Joint Surg Br 91: 670-675.

Baas J, Elmengaard B, Jensen TB, Jakobsen T, Andersen NT, Søballe K (2008) The Effect of pretreating 
morselized allograft bone with RhBMP-2 and/or Pamidronate on the fixation of porous Ti and Ha-coated implants. Biomaterials 29: 2915-2922.

Bouxsein M, Blake C, Luppen C, Cooper J, Wozney J, Seeherman H (2001) Interaction between systemic bisphosphonate therapy and bone formation induced by local delivery of RhBMP-2 in non-human primates. J Bone Miner Res 16: S1, S234.

Chen W-J, Jingushi S, Hirata G, Matsumoto Y, Iwamoto Y (2004) Intramuscular bone induction by the simultaneous administration of recombinant human bone morphogenetic protein 2 and bisphosphonate for autobone graft. Tissue Eng 10: 1652-1661.

Chen W-J, Jingushi S, Jingushi K, Iwamoto Y (2006) In vivo banking for vascularized autograft bone by intramuscular inoculation of recombinant human bone morphogenetic protein-2 and $\beta$-tricalcium phosphate. J OrthopSci 11: 283-288.

Choi J-Y, Kim H-J, Lee Y-C, Cho B-O, Seong H-S, Cho M, Kim S-G (2007) Inhibition of bone healing by pamidronate in calvarial bony defects. Oral Surg Oral Med Oral Pathol Oral Radiol Endod 103: 321-328.

Cooley BC, Daley RA, Toth JM (2005) Long-term BMP-2-induced bone formation in rat island and free flaps. Microsurgery 25: 167-173.

Coxon FP, Helfrich MH, Van't Hof R, Sebti S, Ralston SH, Hamilton A, Rogers MJ (2000) Protein geranylgeranylation is required for osteoclast formation, function, and survival: inhibition by bisphosphonates and GGTI-298. J Bone Miner Res 15: 1467-1476.

DeLustro F, Dasch J, Keefe J, Ellingsworth L (1990) Immune responses to allogeneic and xenogeneic implants of collagen and collagen derivatives. Clin Orthop Relat Res 260: 263-279.

Dimitriou R, Giannoudis PV (2005) Discovery and development of BMPs. Injury 36: S28-S33.

Friedlaender GE, Perry CR, Cole J, Cook S, Cierny G, Muschler GF, Zych GA, Calhoun JH, LaForte AJ, Yin S (2001) Osteogenic protein-1 (Bone Morphogenetic Protein-7) in the treatment of tibial nonunions J Bone Joint Surg Am 83-A Suppl 1: S151-S158.

Friess W (1998) Collagen - biomaterial for drug delivery. Eur J Pharm Biopharm 45: 113-136.

Geesink RGT, Hoefnagels NHM, Bulstra SK (1999) Osteogenic activity of Op-1 Bone morphogenetic protein (BMP-7) in a human fibular defect. J Bone Joint Surg Br 81-B: 710-718.

Giannoudis PV, Einhorn TA, Marsh D (2007) Fracture healing: The diamond concept. Injury 38: S3.

Govender S, Csimma C, Genant HK, Valentin-Opran A, Amit Y, Arbel R, Aro H, Atar D, Bishay M, Borner M, Chiron P, Choong P, Cinats J, Courtenay B, Feibel R, Geulette B, Gravel C, Haas N, Raschke M, Hammacher E, van der Velde D, Hardy P, Holt M, Josten C, Ketterl R, Lindeque B, Lob G, MathevonH, McCoy G, Marsh D, Miller R, Munting E, Oevre S, Nordsletten L, Patel A, Pohl A, Rennie W, Reynders P, Rommens P, Rondia J, Rossouw W, Daneel P, Ruff S, Ruter A, Santavirta S, Schildhauer T, Gekle C, Schnettler R, Segal D, Seiler H, Snowdowne R, Stapert J, Taglang G, Verdonk R, Vogels L, Weckbach A, Wentzensen A, Wisniewski T (2002)
Recombinant human Bone morphogenetic protein-2 for treatment of open tibial fractures: A prospective, controlled, randomized study of four hundred and fifty patients. J Bone Joint Surg Am 84-A: 2123-2134.

Green JR (2005) Zoledronic acid: Pharmacologic profile of a potent bisphosphonate. J Organomet Chem 690: 2439-2448.

Greiner S, Kadow-Romacker A, Lübberstedt M, Schmidmaier G, Wildemann B (2007a) The effect of zoledronic acid incorporated in a poly(D,L-lactide) implant coating on osteoblasts in vitro. J Biomed Mater Res A 80A: 769-775.

Greiner S, Kadow-Romacker A, Wildemann B, Schwabe P, Schmidmaier G (2007b) Bisphosphonates incorporated in a poly(D,L-lactide) implant coating inhibit osteoclast like cells in vitro. J Biomed Mater Res A 83A: 1184-1191.

Greiner SH, Wildemann B, Back DA, Alidoust M, Schwabe P, Haas NP, Schmidmaier G (2008) Local application of zoledronic acid incorporated in a poly(D,Llactide)-coated implant accelerates fracture healing in rats. Acta Orthop79: 717-725.

Harding AK, Aspenberg P, Kataoka M, Bylski D, Tägil M (2008) Manipulating the anabolic and catabolic response in bone graft remodeling: synergism by a combination of local Bmp-7 and a single systemic dosis of zoledronate. J Orthop Res 26: 1245-1249.

Inoda H, Yamamoto G, Hattori T (2007) Rh-BMP2induced ectopic bone for grafting critical size defects: A preliminary histological evaluation in rat calvariae. Int $\mathrm{J}$ Oral Maxillofac Surg 36: 39-44.

Itoh K, Udagawa N, Katagiri T, Iemura S, Ueno N, Yasuda H, Higashio K, Quinn JMW, Gillespie MT, Martin TJ, Suda T, Takahashi N (2001) Bone morphogenetic protein 2 stimulates osteoclast differentiation and survival supported by receptor activator of Nuclear Factor-kB ligand. Endocrinology 142: 3656-3662.

Jakobsen T, Baas J, Bechtold J, Elmengaard B, Søballe K (2010) The effect of soaking allograft in bisphosphonate: A pilot dose-response sudy. Clin Orthopaed Rel Res 468: 867-874.

Jakobsen T, Baas J, Bechtold JE, Elmengaard B, Søballe K (2007) Soaking morselized allograft in bisphosphonate can impair implant fixation. Clin Orthopaed Rel Res 463: 195-201.

Jeppsson C, Åstrand J, Tägil M, Aspenberg P (2003) A combination of bisphosphonate and BMP additives in impacted bone allografts Acta Orthopaed Scand 74: 483489.

Kaneko H, Arakawa T, Mano H, Kaneda T, Ogasawara A, Nakagawa M, Toyama Y, Yabe Y, Kumegawa M, Hakeda Y (2000) Direct stimulation of osteoclastic bone resorption by bone morphogenetic protein (BMP)-2 and expression of BMP receptors in mature osteoclasts. Bone 27: 479 .

Katagiri T, Takahashi N (2002) Regulatory mechanisms of osteoblast and osteoclast differentiation. Oral Dis 8: 147159.

Kato M, Namikawa T, Terai H, Hoshino M, Miyamoto $\mathrm{S}$, Takaoka K (2006a) Ectopic bone formation in mice associated with a lactic acid/dioxanone/ethylene glycol 
copolymer-tricalcium phosphate composite with added recombinant human bone morphogenetic protein-2. Biomaterials 27: 3927-3933.

Kato M, Toyoda H, Namikawa T, Hoshino M, Terai H, Miyamoto S, Takaoka K (2006b) Optimized use of a biodegradable polymer as a carrier material for the local delivery of recombinant human bone morphogenetic protein-2 (RhBMP-2). Biomaterials 27: 2035.

Little D, McDonald M, Bransford R, Godfrey C, Amanat N (2005) Manipulation of the anabolic and catabolic responses with Op-1 and zoledronic acid in a rat critical defect model. J Bone Miner Res 20: 2044-2052.

Little DG, Ramachandran M, Schindeler A (2007) The anabolic and catabolic responses in bone repair. $\mathrm{J}$ Bone Joint Surg Br 89-B: 425-433.

Luckman SP, Hughes DE, Coxon FP, Russell RGG, Rogers MJ (1998) Nitrogen-containing bisphosphonates inhibit the mevalonate pathway and prevent posttranslational prenylation of GTP-binding proteins, including Ras. J Bone Miner Res 13: 581-589.

Marx RE, Sawatari, Y., Fortin, M. \&Broumand, V. (2005) Bisphosphonate-induced exposed bone (osteonecrosis/osteopetrosis) of the jaws: Risk factors, recognition, prevention, and treatment. J Oral Maxillofac Surg 63: 1567-1575.

Mönkkönen J, Similä J, Rogers MJ (1998) Effects of tiludronate and ibandronate on the secretion of proinflammatory cytokines and nitric oxide from macrophages in vitro. Life Sci 62: 95-102.

Mulconrey DS, Bridwell KH, Flynn J, Cronen GA, Rose PS (2008) Bone morphogenetic protein (RhBMP-2) as a substitute for iliac crest bone graft in multilevel adult spinal deformity surgery: minimum two-year evaluation of fusion. Spine 33: 2153-2159.

Okamoto M, Murai J, Yoshikawa H, Tsumaki N (2006) Bone morphogenetic proteins in bone stimulate osteoclasts and osteoblasts during bone development. J Bone Miner Res 21: 1022-1033.

Olsen D, Yang C, Bodo M, Chang R, Leigh S, Baez J, Carmichael D, Perälä M, Hämäläinen E-R, Jarvinen M, Polarek J (2003) Recombinant collagen and gelatin for drug delivery. Adv Drug Deliv Rev 55: 1547-1567.

Rogers M (2003) New insights into the molecular mechanisms of action of bisphosphonates. Curr Pharm Des 9: 2643-2658.

Ruhé PQ, Wolke JGC, Spauwen PHM, Jansen JA (2006) Calcium phosphate ceramics for bone tissue engineering. In: Tissue Engineering and Artificial Organs (Bronzino JD, ed), Taylor \& Francis Group, Boca Raton, FL, pp 38-1-18.

Saito N, Murakami N, Takahashi J, Horiuchi H, Ota H, Kato H, Okada T, Nozaki K, Takaoka K (2005) Synthetic biodegradable polymers as drug delivery systems for bone morphogenetic proteins. Adv Drug Deliv Rev 57: 1037-1048.

Saito N, Okada T, Horiuchi H, Murakami N, Takahashi J, Nawata M, Ota H, Miyamoto S, Nozaki K, Takaoka K (2001a) Biodegradable poly-D,L-lactic acid-polyethylene glycol block copolymers as a BMP delivery system for inducing bone. J Bone Joint Surg Am 83-A Suppl 1: S92S98.
Saito N, Okada T, Horiuchi H, Murakami N, Takahashi J, Nawata M, Ota H, Nozaki K, Takaoka K (2001b) A biodegradable polymer as a cytokine delivery system for inducing bone formation. Nat Biotech 19: 332.

Saito N, Okada T, Horiuchi H, Ota H, Takahashi J, Murakami N, Nawata M, Kojima S, Nozaki K, Takaoka K (2003) Local bone formation by injection of recombinant human bone morphogenetic protein-2 contained in polymer carriers. Bone 32: 381-386.

Saito N, Okada T, Toba S, Miyamoto S, Tanaka K (1999) New synthetic absorbable polymers as BMP carriers: plastic properties of poly-D,L-lactic acidpolyethylene glycol block copolymers. J Biomed Mater Res 47: 104-110.

Saito N, Takaoka K (2003) New synthetic biodegradable polymers as BMP carriers for bone tissue engineering. Biomaterials 24: 2287-2293.

Schindeler A, Morse A, Peacock L, Mikulec K, Yu N, Liu R, Kijumnuayporn S, McDonald M, Baldock P, Ruys A, Little D (2010) Rapid cell culture and pre-clinical screening of a transforming growth factor-beta (TGF-beta) inhibitor for orthopaedics. BMC Musculoskel Dis 11: 105.

Schindeler A, Ramachandran M, Godfrey C, Morse A, McDonald M, Mikulec K, Little DG (2008) Modeling bone morphogenetic protein and bisphosphonate combination therapy in wild-type and Nf1 haploinsufficient mice J Orthop Res 26: 65-74.

Schmidmaier G, Wildemann B, Ostapowicz D, Kandziora F, Stange R, Haas NP, Raschke M (2004) Longterm effects of local growth factor (IGF-I and TGF-b1) treatment on fracture healing. A safety study for using growth factors. J Orthop Res 222: 514-519.

Schmidmaier G, Wildemann B, Stemberger A, Haas NP, Raschke M (2001) Biodegradable poly(D,L-lactide) coating of implants for continuous release of growth factors. J Biomed Mat Res 58: 449-455.

Seeherman H, Blake C, Luppen C, Bouxsein M, Li J, Wozney J (2000) RhBMP-2 stimulates remodeling and bone formation in a nonhuman primate core defect model. Proc 46th Ann Meet Orthopaed Res Soc, Orlando, FL 25: 1042.

Seeherman H, Kiker-Head C, Li X, Bouxsein M, Wozney J (1998) RhBMP-2 stimulates bone formation in a femoral head core decompression model in adult sheep. Proc 44th Ann Meet Orthopaed Res Soc, New Orleans, LA, pp 65.

Seeherman H, Li J, Blake C, Gavin D, Wozney J, Bouxsein M (2001) Histology indicates bisphosphonate limits transient resorption without decreasing bone induction in nonhuman primate core defects treated with RhBMP-2/ACS. J Bone Miner Res 16: S1, S438.

Seeherman H, Li XJ, Bouxsein ML, Wozney JM (2010) RhBMP-2 induces transient bone resorption followed by bone formation in a nonhuman primate core-defect model. J Bone Joint Surg Am 92: 411-426.

Tägil M, Aspenberg P, Åstrand J (2006) Systemic zoledronate precoating of a bone graft reduces bone resorption during remodeling. Acta Orthop77: 23-26.

Termaat MF, Den Boer FC, Bakker FC, Patka P, Haarman HJTM (2005) Bone morphogenetic proteins: Development and clinical efficacy in the treatment of 
fractures and bone defects. J Bone Joint Surg Am 87: $1367-$ 1378.

Thiébaud D, Sauty A, Burckhardt P, Leuenberger P, Sitzler L, Green JR, Kandra A, Zieschang J, Ibarra de Palacios P (1997) An in vitro and in vivo study of cytokines in the acute-phase response associated with bisphosphonates. Calcif Tissue Int 61: 386-392.

Vaccaro AR, Patel T, Fischgrund J, Anderson DG, Truumees E, Herkowitz H, Phillips F, Hilibrand A, Albert T (2003) A pilot safety and efficacy study of Op-1 putty (RhBMP-7) as an adjunct to iliac crest autograft in posterolateral lumbar fusions. Eur Spine J 12: 495-500.

Yang SF, Du, ZH, Leong KF, Chua CK (2001) The design of scaffolds for use in tissue engineering. Part I. Traditional factors. Tissue Eng 7: 679-689.

Yu NYC, Schindeler A, Little DG, Ruys AJ (2010) Biodegradable poly(A-hydroxy acid) polymer scaffolds for bone tissue engineering. J Biomed Mater Res B Appl Biomater 93B: 285-295.

Zegzula HD, Buck DC, Brekke J, Wozney JM, Hollinger JO (1997) Bone formation with use of RhBMP2 (Recombinant Human Bone Morphogenetic Protein-2). J Bone Joint Surg Am 79: 1778-1790.

\section{Discussion with Reviewers}

Reviewer I: I would like to know whether other growth factors or bisphosphonates might be useful testing in such a setting.

Authors: In future studies it may be worthwhile to confirm the effects of alternative pro-osteogenic growth factors, such as rhBMP-2 in combination with alternative bisphosphonates or other anti-osteoclastic agents. This study serves as a model where archetypical pro-anabolic and anti-catabolic agents are used. Bisphosphonates were of specific interest due to the previously reported concerns with local dosing, particularly with Pamidronate. Zoledronic acid would be another bisphosphonate of interest as its greater potency could allow for lower doses to be used locally to generate a comparable biological effect.

Reviewer I: Why do authors think, that variation in dosage of BMP7 is not necessary?

Authors: In another study where BMP dose was varied (in the absence of bisphosphonate), bone formed in a BMP dose dependent manner. However, in all cases the bone architecture (a cortical shell with minimal interior bone) was observed. This phenomenon is well described and not novel. We sought to test the effects of an anti-catabolic drug with the hypothesis that a moderate dose could improve bone retention and lead to greater net bone with different architecture.

Reviewer II: What was the rationale for giving the animals in the 8 weeks group injections for 21 instead of 19 days, as was done with the 3 weeks group? Also, why was the initial number of animals 9 in locally treated groups and 8 in systemically treated?
Authors: In the 3 week group mice were dosed throughout the post-operative time with no dose on the 3 week date as this was the cull point. It was observed that the polymer was largely unresorbed at 3 weeks we hypothesised that a longer follow up could allow for the polymer to completely resorb. Bisphosphonate dosing was allowed to continue for the full 3 weeks so that systemic anti-resorptive therapy could continue for this entire time. This was not an issue for local dosing. An improved explanation has been added to the methods section.

Reviewer II: It is of course never wrong to use nonparametric tests, but the text suggests that this is required because $\mathrm{n}<10$, which is not correct. I suppose the reason has to do with data distribution?

Authors: Standard parametric tests are based upon specific assumptions including a normal data distribution and equivalent variances. Tests to demonstrate normal distribution and equal variances require higher $n$ values (or prior validation of these tests using the model system) and $\mathrm{n}<10$ was insufficient to prove these assumptions. Notably, non-parametric tests are more stringent than parametric tests and, as noted by the reviewer, their use is not incorrect.

Reviewer II: Why did you choose to use $\mu \mathrm{CT}$ instead of quantitative histology?

Authors: Bone was quantified by 3-dimensional $\mu \mathrm{CT}$ analysis, which allowed for volumetric measurement. As induced bone nodules could vary in shape, the differences in cross sectional area depending where a histological section was taken would be a source of variability. A volumetric metric was therefore selected as a more accurate method of quantifying bone.

Reviewer II: In Fig. 2, is there any explanation for the large variation in the $3 \mathrm{mg} / \mathrm{kg}$ PAM group in comparison to the other groups?

Authors: The $3 \mathrm{mg} / \mathrm{kg}$ dose can be considered a high dose, above the level of clinical relevance. It is possible that such high doses could produce more variable results due to their potential to produce adverse effects in a stochastic fashion. However, the exact reasons for this variation remain unclear and we have reported the essential finding while minimising our editorial speculation.

Reviewer II: There appears to be a discrepancy between Figs. 2 and 4, because in Fig. 4 the medium dose shows the most dense bone, whereas in Fig. 2 it is the low dose. Are the images in Fig. 4 representative?

Authors: Representative images for Fig. 2 were selected based on the median and every effort was made to choose a consistent orientation. However, in the case of Fig. 4, this is descriptive histology showing regions of slides representing the overall trend of osteoclast staining. It should not be extrapolated that the apparent differences in bone in Fig. 4 are representative, particularly as zoomed out views and quantification (Fig. 2) accurately report bone formation. 
Reviewer III: Is the non-osseous muscle pouch model valid for bone formation in an osseous site like a fracture? Authors: We have not specifically used these results to extrapolate to fracture healing, although we postulate this form of implant may be useful in the repair of critical sized defects (one of the goals of bone tissue engineering). In critical sized defects, the anabolic response is insufficient to allow for normal bone repair and an exogenous anabolic stimulus is required. The formation of ectopic bone is a situation where the entire anabolic bone stimulus is, by definition, exogenous. Nevertheless, this is a proof of principle study looking at local dosing of BMPs and bisphosphonates and future work will be required using critical defect models to look at the use of these implants in more clinically relevant models.

The use of a system featuring induced versus found in the muscle compartment versus committed osteoprogenitors found in a healing fracture has been added to the paper discussion.

Reviewer III: The authors claim that collagen is a rather sub-optimal carrier for both BMP and bisphosphonates. I agree, but what do we know about PDLLA as carrier for BMP. Why did you choose PDLLA, more than that it is common and inexpensive - which is the only reason stated? Maybe there are better polymers, which can aid in for example the initial peak of released BMP, which probably is beneficial, or preventing the BMP to be stuck in the polymer. Regarding bisphosphonate delivery, maybe a fast resolving calcium-based bone substitute would be more controllable? The problem with most previous studies, the present being an exception, is that concentration-over-timecurves are never presented so we really do not know when the drug is released or of achieved concentrations. Why did you choose a rather slowly dissolving polymer like PDLLA? Have you tested other faster or slower dissolving carriers? Please explain the choice of polymer.

Authors: As noted in the text, PDLLA has been previously used clinically and experimentally to deliver growth factors, BMPs, and bisphosphonates. It is also a low-cost compound that is ultimately degradable into biocompatible by-products (carbon dioxide and water). We concur with the reviewer that other polymers may have a superior capacity to deliver BMPs, but these will also need to be directly compared and validated. In this study we have selected PDLLA as a relatively slowly dissolving polymer. Laboratory tests using an alternative faster degrading polymer using solvent casting revealed high malleability leading to inconsistencies in pellet shape and size, thus leading PDLLA to be the most practical choice for this proof-of-principle study. Ceramic scaffold are often slower degrading and their radio-opaque nature makes it challenging to quantify bone formation using radiography/ $\mu \mathrm{CT}$, and were not considered suitable for this type of experimental design. Future translational work will examine a range of other polymers and fabrication strategies that will likely improve biodegradability and drug release to yield an optimal outcome. 